\title{
NOTE:
}

\section{Comparing the Chemical Characteristics of Pectin Isolated from Various Indonesian Fruit Peels}

\author{
Siti Susanti ${ }^{1 *}$, Anang Mohamad Legowo ${ }^{1}$, Nurwantoro $^{1}$, Silviana $^{2}$, and Fahmi Arifan $^{3}$ \\ ${ }^{1}$ Food Technology Division, Department of Agriculture, Faculty of Animal and Agricultural Sciences, Diponegoro University, \\ Jl. Prof. Soedarto SH, Tembalang, Semarang 50275, Central Java, Indonesia
}

${ }^{2}$ Department of Chemical Engineering, Faculty of Engineering, Diponegoro University, Jl. Prof. Soedarto SH, Tembalang, Semarang 50275, Central Java, Indonesia

${ }^{3}$ Diploma Program of Chemical Engineering, Faculty of Vocational School, Diponegoro University, Jl. Prof. Soedarto SH, Tembalang, Semarang 50275, Central Java, Indonesia

\section{*Corresponding author:}

email: sitisusanti@live.undip.ac.id

Received: September 16, 2020

Accepted: February 9, 2021

DOI: $10.22146 /$ ijc.59799

\begin{abstract}
The Indonesian pectin manufacturing industry is underdeveloped, and pectin is imported to meet its increasing demand; we attempted to isolate pectins from various fruit peels, such as orange peel (OP), papaya peel (PP), mango peel (MP), watermelon peel (WP), and chayote peel (CP) and investigated their chemical characteristics (equivalent weight of the extracted pectins and their moisture, ash, methoxyl, and galacturonic acid (GA) contents). Acid extraction, purification, precipitation, and drying processes were used to process the isolated pectins. We examined their chemical properties for conformance to quality standards advised by the International Pectin Producers Association (IPPA). The moisture (except OP pectin) and ash contents (except PP pectin) of the extracted pectins were within the limit set by IPPA. However, the equivalent weight (W eq) of any of the isolated pectins did not satisfy IPPA standards. The methoxyl contents of the pectins isolated from OP, WP, and CP satisfied IPPA standards. High methoxyl pectins were isolated from $P P$ and MP. The galacturonic acid contents of the isolated pectins were higher than the acceptable limit of the GA level. Thus, OP, PP, MP, $W P$, and CP are potential sources of pectin.
\end{abstract}

Keywords: natural source; chemical; pectin; fruit peels

\section{- INTRODUCTION}

Pectin is a polysaccharide and a functional ingredient utilized in the food and pharmaceutical industries. Natural pectin can be isolated from the cell walls of different plant parts [1]. The fruit peel, which is considered a waste product in the food and fruit-based industries, is also a source of natural pectin [2].

Pectin is used as a stabilizer in food and has emerged as an important ingredient used in the food industry. The last decade has seen a growing interest in Indonesian culinary. This has resulted in a gradual increase in the demand for pectin [3]. Unfortunately, pectin is still imported into Indonesia as the pectin manufacturing industry in Indonesia is still undeveloped. However, a huge amount of waste that can be potential sources of pectin is generated each year by the fruit industries present in the country [3]. The utilization of fruit peels as sources of pectin is still in its nascent stage.

The peels of various indigenous fruits (such as banana, durian, grapefruit, and papaya peels) can be potential sources of natural pectin [4]. Various extraction and isolation methods for obtaining pectin have been reported. The isolation methods employed can potentially influence the yield and chemical characteristics of pectin.

This study outlined the procedure to isolate pectin from various fruit peels (mango, orange, papaya, 
watermelon, and chayote) using the following reported protocols of extraction and studied the characteristics of the isolated pectins. It also investigated whether the quality of the isolated pectin samples adheres to the quality standards advised by the International Pectin Producers Association (IPPA) [5]. Herein, we present scientific data that can be potentially utilized for developing the pectin manufacturing industry by using indigenous fruit peels as sources of natural pectin. The use of fruit peels as sources of natural pectin can utilize the waste generated from fruit-based food industries. Thus, optimal waste management can be achieved, leading to environmental preservation.

\section{- EXPERIMENTAL SECTION}

\section{Materials}

Orange peel (OP), papaya peel (PP), mango peel (MP), watermelon peel (WP), and chayote peel (CP) were used as the pectin sources. The fruit peels were collected from fruit-based food industries in different parts of Semarang City, Central Java Province, Indonesia. The chemicals used in this study were hydrochloric acid $(\mathrm{HCl})$, phenolphthalein, 96\% ethanol, sodium hydroxide $(\mathrm{NaOH})$, and distilled water.

\section{Instrumentation}

Dry fruit peels were powdered by using an electric metal grinder (Nima, Japan). Extraction equipment series such as ring stand clamp (Thomas ${ }^{\bullet}$ Scientific, USA), laboratory glass thermometer (NFS 200 Celsius degree, RTEK, India), portable magnetic stirrer (Z693448-1EA, Merck), heating mantle (E103, MTOPs, Korea), and three-neck distilling flask (500 mL, PYREX ${ }^{\oplus}$, USA) were used for pectin extraction.

\section{Procedure}

The fruit peels were washed to remove all traces of dirt. After that, the fruit peels were sun-dried to obtain dry matter with an average moisture content of $8.64 \%$ and then powdered.

\section{Pectin isolation}

Pectin was isolated from various fruit peel powders following a previously reported protocol [6] that was slightly modified. The peel powder $(50 \mathrm{~g})$ was suspended in distilled water $(250 \mathrm{~mL})$. Subsequently, $\mathrm{HCl}(1 \mathrm{~N}$, $0.5 \mathrm{~mL}$ ) was added to the solution, and the suspension was heated at $80^{\circ} \mathrm{C}$ for $120 \mathrm{~min}$. The mixture $(\mathrm{pH}=2.8)$ was filtered through two layers of cheesecloth. Following this, the filtrate was coagulated using 96\% ethanol (filtrate: ethanol ratio was 1:1 by volume), and the mixture was stirred continuously for $15 \mathrm{~min}$. Subsequently, the isolated pectin was washed with ethanol $(5 \mathrm{~mL})$. The pectin was dried in an oven at $40{ }^{\circ} \mathrm{C}$ for $8 \mathrm{~h}$, ground, and then sifted to obtain fine powdered pectin.

\section{Determination of chemical characteristic of pectin}

The chemical characteristics of the isolated pectins (obtained from OP, PP, MP, WP, and CP) were analyzed. The equivalent weights (W eq) of the pectins and the moisture, ash, galacturonic acid (GA), and methoxyl contents were determined. Six different samples of each pectin were used for testing each of these parameters. The moisture and ash contents of pectins were determined by the following protocols outlined [7]. $\mathrm{W}$ eq of the pectins and the methoxyl and GA contents were determined following the process established by Ranganna [8].

\section{Statistical analysis}

All data were statistically tested using the analysis of variance technique. Following this, Duncan multiple range tests (significance level: 5\%) were conducted to analyze the obtained data [9].

\section{- RESULTS AND DISCUSSION}

Generally, the fruit peel is not utilized to its full extent and is often discarded as a waste product that causes environmental problems (especially water pollution). Cell walls that form the fruit peel tissue contain pectin, which is a form of fiber [10]. Therefore, fruit peels can be potentially used as a natural source of pectin. Several researchers have successfully isolated pectin from fruit peels $[6,11-13]$. Some researchers from Indonesia have also successfully isolated pectin from fruit peels [14-16]. Although various methods have been reported for pectin extraction, almost all extraction methods require the use of an acid solution. The acid of 
interest used in our studies is hydrochloric acid $(\mathrm{HCl}, 1$ $\mathrm{N}$ ), which is a strong acid and ensures efficient pectin extraction (compared with other acids such as acetic acid). The lower the $\mathrm{pH}$, the faster the rate of degradation of the extracted material. The extraction process runs smoothly when the hydrolytic molecules are quickly released from the galacturonic acid chains [16].

We used pectin isolated from OP, PP, MP, WP, and $\mathrm{CP}$ for the studies. To ensure that the fruit peel contained sufficient pectin, preliminary research (involving the alcohol test) was conducted with the peel samples [17]. The fruits were squeezed to obtain the fruit liquid. Following this, four tablespoons of ingredients were added to one spoonful of the juice. High pectin content is indicated by the formation of thick clots in the mixture. The formation of fewer clots with a liquid-like consistency indicates low pectin content.

Peels of ripe fruits were used as sources of pectin because they contain sufficient quantities of pectin that can be used for analyzing the properties of pectin. Ripe fruits contain protopectin that can be easily broken down by fruit ripening hormones. The extent of conversion of protopectin to pectin (and finally to pectic acid) increases as the fruit ripens. Pectic acid is highly soluble in fruit liquid [10]. Therefore, the amount of pectin in the peel of ripe fruit is more than that present in the peel of raw fruit.

The extraction methods affect the characteristics of pectin. The chemical properties of pectin affect the physical characteristics and quality of pectin. The quality standards advised by IPPA are commonly used as references for evaluating the quality of pectin. We studied the chemical characteristics of pectin obtained from $O P$, PP, MP, WP, and CP.

\section{Moisture Content of Pectin}

The moisture content of food products is an important determinant of the durability of food products because it is related to the microbial activity in stored products. Food products with low moisture content are relatively more stable and have a longer shelf-life than food products with high moisture content. As shown in Fig. 1, the moisture content of pectin extracted from OP was the maximum (15.03\%). Pectins extracted from other fruit peels exhibited a lower moisture content ( $\mathrm{p} \leq 0.05)$. It was assumed that an inefficient drying process was responsible for the retention of water in the pectin sample isolated from OP, resulting in the high moisture content of the sample [18]. We observed that the pectin sample (especially the sample extracted from OP) could not be effectively dried by heating it at $40^{\circ} \mathrm{C}$ for $8 \mathrm{~h}$. The optimum drying temperature for drying the pectin extracted from OP (moisture content $<12 \%$ ) was found to be $50{ }^{\circ} \mathrm{C}$. The sample should be heated at $50{ }^{\circ} \mathrm{C}$ for 6 $\mathrm{h}$ for efficient drying [18]. According to IPPA guidelines, the acceptable moisture level in pectin is $\leq 12 \%$. Thus, the moisture contents of pectin extracted from PP, MP, $\mathrm{WP}$, and $\mathrm{CP}$ were within the permissible limit of moisture content [5].

\section{Ash Content of Pectin}

Ash is the inorganic residue obtained from the combustion of organic matter. The ash content can be used to estimate the mineral content of the material as well as to determine the purity of pectin. The higher the ash content, the lower the pectin purity. Fig. 2 reveals that the ash contents of pectin, extracted from the fruit peels, were within $(\mathrm{p} \leq 05)$ the IPPA-recommended upper limit of ash content $(\leq 10 \%)$. However, the ash content of pectin extracted from PP was significantly higher than the acceptable limit of ash content $(12.06 \%$, $\mathrm{p} \leq$ 0.05). Thus, OP, MP, WP, and CP are the potential

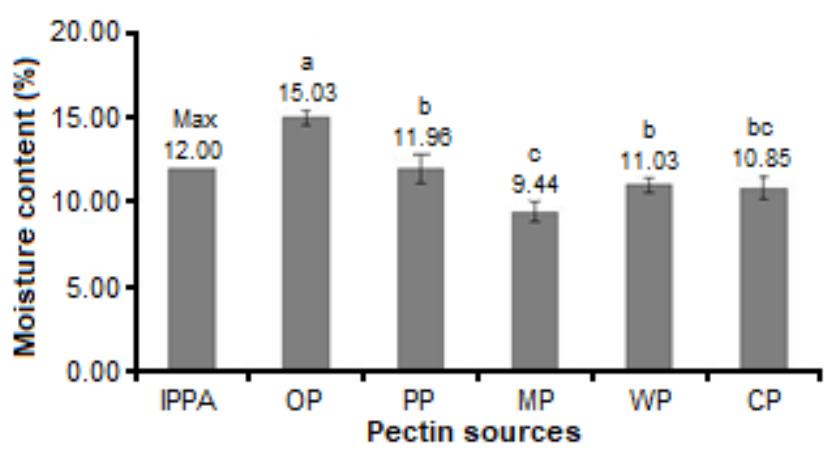

Fig 1. Moisture content (\%) of pectin isolated from various fruit peels such as $\mathrm{OP}, \mathrm{PP}, \mathrm{MP}, \mathrm{WP}$, and $\mathrm{CP}$. The data are expressed as mean \pm STDEV. The standards advised by IPPA are taken as reference. The letters above each bar graph represent the significant differences between the groups 


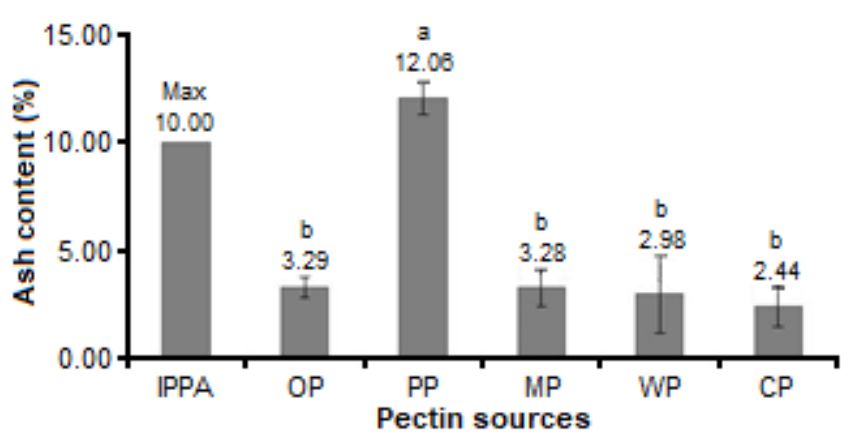

Fig 2. Ash content (\%) of pectin isolated from various fruit peels such as OP, PP, MP, WP, and CP. The data are expressed as the mean \pm STDEV. The standard laid down by IPPA is taken as the reference. The letters above each bar graph represent the significant differences between the groups

sources of natural pectin because they can potentially produce pure pectin.

The raw materials used and the extraction and isolation methods employed for pectin extraction determined the ash content of pectin. The amount and composition of the minerals present in the raw materials can potentially influence the purity of pectin [16]. The ash content increased as the extraction time increased. The ash content in pectin extracted from PP was found to be the maximum when the extraction time was 120 min (Fig. 2). Thus, the extraction time for obtaining pectin from PP should be such that high-quality pectin (in terms of purity) can be obtained. Although an extraction time of $120 \mathrm{~min}$ afforded the maximum amount of pectin, the optimal extraction time was found to be in the range of 60-90 $\mathrm{min}$. Highly pure pectin with low ash content was obtained under this optimum extraction condition [14,19].

\section{Equivalent Weight (W eq) of Pectin}

The high and low pectin levels caused by the presence of free GA groups in the molecular chain of pectin can be estimated from the $\mathrm{W}$ eq values [17]. Fig. 3 shows that the $\mathrm{W}$ eq of the isolated pectins was significantly higher than the IPPA-recommended acceptable maximum limit of $\mathrm{W}$ eq $(\leq 800 \mathrm{mg})$. The $\mathrm{W}$ eq of CP pectin $(\mathrm{p} \leq 0.05)$ was the highest $(9,394 \mathrm{mg})$. Different $\mathrm{W}$ eq was observed for different pectin samples because fruit peels of different fruits were used as the raw materials. The extraction method used for obtaining the pectin samples and the titration process used for analyzing the samples can potentially affect the $\mathrm{W}$ eq of the pectins [13]. The pectin chains are depolymerized (forming pectic acids) when the extraction time is significantly long (120 min). It also leads to an increase in the number of unesterified GA groups.

\section{Methoxyl Content of Pectin}

The methoxyl contents of pectins are a determinant of the gel-forming abilities of pectins [20]. Based on the methoxyl content, pectin is divided into two groups: high methoxyl pectin (HMP, > 7.12\%) and low methoxyl pectin (LMP, 2.50-7.12\%). The methoxyl levels in pectins extracted from OP, WP, and CP were lower than the IPPA prescribed maximum acceptable level. Hence, they were categorized as LMPs. The calculated methoxyl levels in pectins extracted from PP and MP were higher than the IPPA-recommended maximum permissible level of methoxyl content. Hence, they were categorized as HMPs (Fig. 4). The higher the amount of methoxyl in pectin, the greater the ability of pectin to thicken a medium.

\section{Ga Content of Pectin}

The purity of pectin can be determined by its GA content [17]. The purity of pectin increases as the GA content increases. This is caused by a decrease inorganic content. The GA contents of pectin extracted from different fruit peels were greater than the acceptable limit

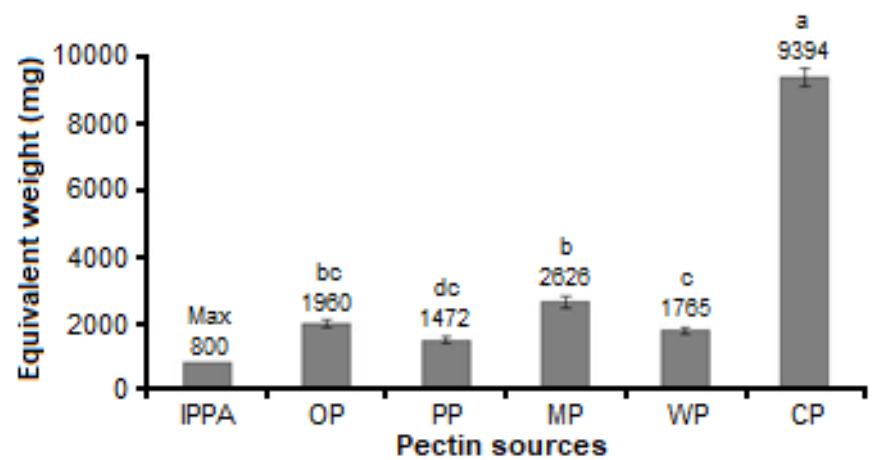

Fig 3. Equivalent weight $(\mathrm{mg})$ of pectin isolated from various fruit peels such as $\mathrm{OP}, \mathrm{PP}, \mathrm{MP}, \mathrm{WP}$, and $\mathrm{CP}$. The data are expressed as the mean \pm STDEV. The standard laid down by IPPA is taken as the reference. The letters above each bar graph represent the significant differences between the groups 


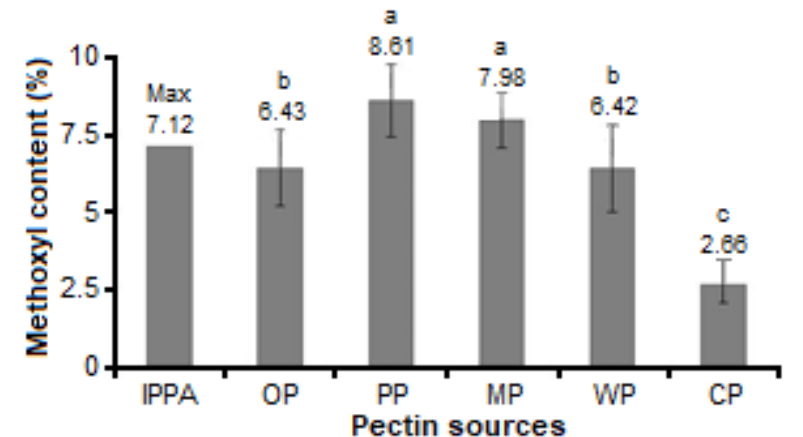

Fig 4. Methoxyl content (\%) of pectin isolated from various fruit peels such as $\mathrm{OP}, \mathrm{PP}, \mathrm{MP}, \mathrm{WP}$, and $\mathrm{CP}$. The data are expressed as the mean \pm STDEV. The standard laid down by IPPA is taken as the reference. The letters above each bar graph represent the significant differences between the groups

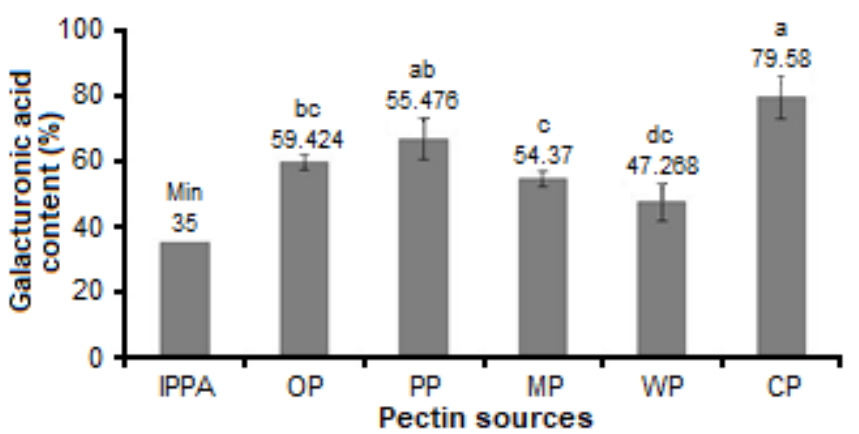

Fig 5. GA content (\%) of pectin isolated from various fruit peels such as $\mathrm{OP}, \mathrm{PP}, \mathrm{MP}, \mathrm{WP}$, and $\mathrm{CP}$. The data are expressed as the mean \pm STDEV. The standard laid down by IPPA is taken as the reference. The letters above each bar graph represent the significant differences between the groups

of GA content (set by IPPA). The maximum amount of GA was found in CP pectin (Fig. 5). Thus, OP, PP, MP, $\mathrm{WP}$, and $\mathrm{CP}$ can potentially produce high-quality pectin.

\section{- CONCLUSION}

Pectins were extracted from the peels of orange, papaya, mango, watermelon, and chayote, and they exhibited different chemical characteristics. These different chemical characteristics can be attributed to the extraction methods used to isolate the pectins and the type of raw materials used as the pectin source. All the fruit peels used for carrying out the studies can be potentially used as alternative sources of pectin. However, the chemical characteristics of the extracted pectins do not strictly adhere to the quality standards advised by IPPA. Thus, different extraction methods and alternate pectin sources should be continuously explored to achieve the indigenous production of high-quality pectin.

\section{- REFERENCES}

[1] Buchanan, B.B., Gruissem, W., and Jones, R.L., 2015, Biochemistry and Molecular Biology of Plants, $2^{\text {nd }}$ Ed., John Wiley and Sons, New York, USA.

[2] Sundarraj, A.A., and Ranganathan, T.V., 2017, A review - Pectin from agro and industrial waste, Int. J. Appl. Environ. Sci., 12 (10), 1777-1801.

[3] Naqash, F., Masoodi, F.A., Rather, S.A., Wani, S.M., and Gani, A., 2017, Emerging concepts in the nutraceutical and functional properties of pectin, Carbohydr. Polym., 168, 227-239.

[4] Petkowicz, C.L.O., Vriesmann, L.C., and Williams, P.A., 2017, Pectins from food waste: Extraction, characterization and properties of watermelon rind pectin, Food Hydrocolloids, 65, 57-67.

[5] International Pectin Producers Association (IPPA), 2014, Pectin Commercial Production and Pectin in Organic Food Products, https://ippa.info.

[6] Hamidon, N.H., and Zaidel, D.N.A., 2017, Effect of extraction conditions on pectin yield extracted from sweet potato peels residues using hydrochloric acid, Chem. Eng. Trans., 56, 979-984.

[7] Grassino, A.N., Barba, F.J., Brnčić, M., Lorenzo, J.M., Lucini, L., and Brnčić, Z.R., 2018, Analytical tools used for the identification and quantification of pectin extracted from plant food matrices, wastes and by-products: A review, Food Chem., 266, 47-55.

[8] Ranganna, S., 1995, Handbook of Analysis and Quality Control for Fruit and Vegetable Products, Tata McGraw-Hill Publishing Company Limited, New Delhi, India.

[9] Elmore, J.G., Wild, D.M.G., Nelson, H.D., and Katz, D.L., 2020, Jekel's Epidemiology, Biostatistics and Preventive Medicine and Public Health, $5^{\text {th }}$ Ed., Elsevier Health Sciences, London.

[10] Lara-Espinoza, C., Carvajal-Millán, E., BalandránQuintana, R., López-Franco, Y., and Rascón-Chu, 
A., 2018, Pectin and pectin-based composite materials: beyond food texture, Molecules, 23 (4), 942.

[11] Akili, M.S., Ahmad, U., and Suyatma, N.E., 2012, Karakteristik edible film dari pectin hasil ekstraksi kulit pisang, JTEP, 26 (1), 39-46.

[12] Guo, X., Han, D., Xi, H., Rao, L., Liao, X., Hu, X., and $\mathrm{Wu}, \mathrm{J} ., 2012$, Extraction of pectin from navel orange peel assisted by ultra-high pressure, microwave or traditional heating: A comparison, Carbohydr. Polym., 88 (2), 441-448.

[13] Freitas, C.M.P., Sousa, R.C.S., Dias, M.M.S., and Coimbra, J.S.R., 2020, Extraction of pectin from passion fruit peel, Food Eng. Rev., 12 (4), 460-472.

[14] Djenar, N.S., and Suryadi, J., 2020, Microwave power and $\mathrm{pH}$ regulating solution effect on characteristics of pectin from sukun peel (Artocarpus altilis) using Microwave Assisted Extraction (MAE), Proceedings of the International Seminar of Science and Applied Technology (ISSAT 2020), Politeknik Negeri Bandung, Bandung, 24-25 November 2020.

[15] Hasanah, U., Setyowati, M., Edwarsyah, Efendi, R., Safitri, E., Idroes, R., Heng, L.Y., and Sani, N.D., 2018, Isolation of pectin from coffee pulp Arabica Gayo for the development of matrices membrane,
IOP Conf. Ser.: Mater. Sci. Eng., 523, 012014.

[16] Raji, Z., Khodaiyan, F., Rezaei, K., Kiani, H., Schultz, M, and Zanganeh, S., 2020, The influence of particle size and acid type on pectin extraction, IJFAS, 9 (1), 1-4.

[17] Paasikallio, T., Huuskonen, A., and Wiebe, M.G., 2017, Scaling up and scaling down the production of galactaric acid from pectin using Trichoderma reesei, Microb. Cell Fact., 16 (1), 119.

[18] Hosseini, S.S., Khodaiyan, F., and Yarmand, M.S., 2016, Optimization of microwave assisted extraction of pectin from sour orange peel and its physicochemical properties, Carbohydr. Polym., 140, 59-65.

[19] Su, D.L., Li, P.J., Quek, S.Y., Huang, Z.Q., Yuan, Y.J., Li, G.Y., and Shan, Y., 2019, Efficient extraction and characterization of pectin from orange peel by a combined surfactant and microwave assisted process, Food Chem., 286, 1-7.

[20] Xie, F., Gu, B.J., Saunders, S.R., and Ganjyal, G.M., 2021, High methoxyl pectin enhances the expansion characteristics of the cornstarch relative to the low methoxyl pectin, Food Hydrocolloids, $110,106131$. 